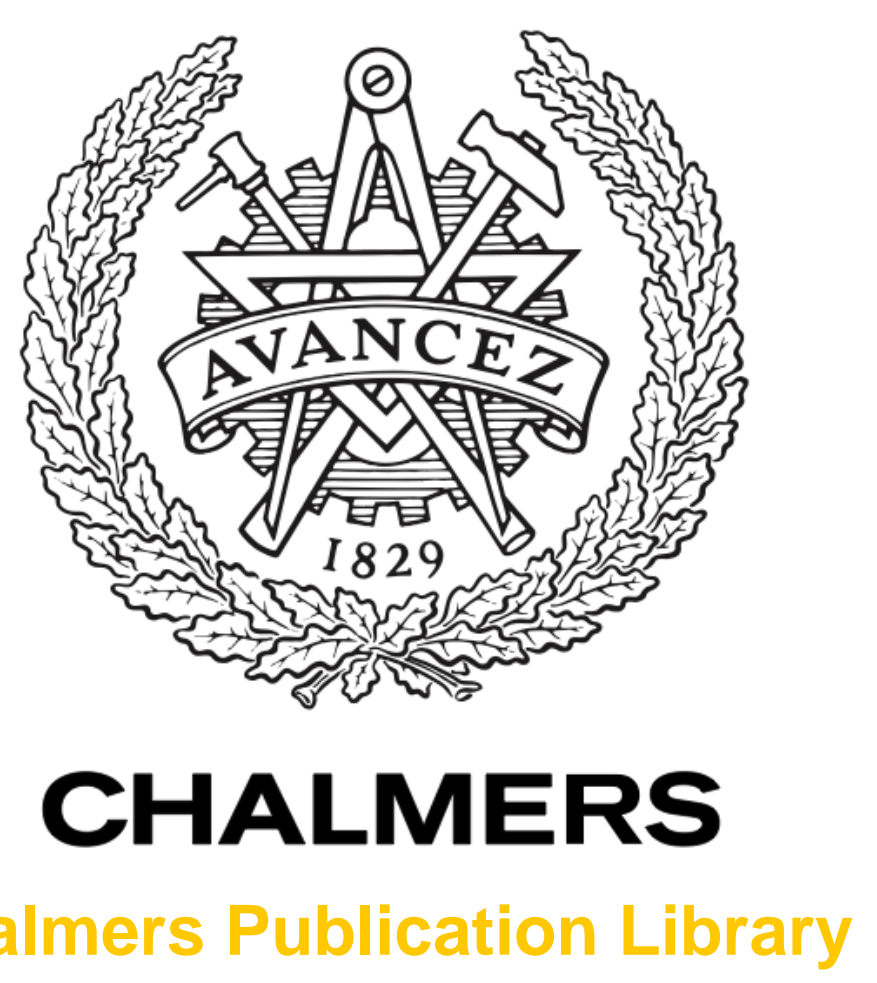

\title{
Insights into Physician Scheduling: a case study of public hospital departments in Sweden
}

This document has been downloaded from Chalmers Publication Library (CPL). It is the author's version of a work that was accepted for publication in:

International journal of health care quality assurance/MCB University Press (ISSN: 09526862)

Citation for the published paper:

Santos, M. ; Eriksson, H. (2014) "Insights into Physician Scheduling: a case study of public hospital departments in Sweden". International journal of health care quality assurance/MCB University Press, vol. 27(2),

Downloaded from: http://publications.lib.chalmers.se/publication/195014

Notice: Changes introduced as a result of publishing processes such as copy-editing and formatting may not be reflected in this document. For a definitive version of this work, please refer to the published source. Please note that access to the published version might require a subscription. 


\section{Insights into physician scheduling}

Author 1: Marco António Ferreira Rodrigues Nogueira dos Santos, MSc., PhD-student at Division of Quality Sciences/Centre for Healthcare Improvement, University/Chalmers University of Technology, Gothenburg, Sweden, tel: +46(0)31 772 4885, e-mail: marco.santos@chalmers.se

Author 2: Henrik Kurt Olof Eriksson, MSc., PhD, researcher at Division of Quality Sciences/Centre for Healthcare Improvement, Chalmers University of Technology, Gothenburg, Sweden, tel: +46(0)31 772 8184, e-mail: henrik.eriksson@chalmers.se

Corresponding author: Marco António Ferreira Rodrigues Nogueira dos Santos Corresponding Author's Email: marco.santos@chalmers.se

\section{Acknowledgments (if applicable):}

The authors express their gratitude to Associate Professor Ida Gremyr, Kristian Siverbo and Sune Andreasson for their valuable comments that enhanced the article's quality.

\section{Structured Abstract:}

Purpose: To describe current physician scheduling and concomitant opportunities for improvement in Sweden's public hospitals.

Design/Methodology/Approach: Staff in 13 departments, spread geographically across Sweden, covering seven different specialties, participated in the study. Data were collected through interviews with individuals creating physician schedules. Staff in all departments investigated provided documents they used for physician scheduling.

Findings: Physician scheduling required that patient, physician, non-physician staff, room and equipment are coordinated. A six-step process for creating physician schedules was distinguished: (i) capacity and demand; (ii) goal and schedule setting; (iii) vacation and leave requests; (iv) schedule creation; (v) schedule revision and (vi) schedule execution. Several opportunities for improvement were outlined; e.g., overreliance on memory, uncoordinated resources and redundant-data entry.

Practical implications: To improve physician scheduling and enable timeliness, three approaches are proposed: (i) reinforcing centralization, (ii) creating learning opportunities and (iii) improving integration.

Research limitations/implications: Previous physician-scheduling studies lend an exploratory character to this study, which excluded non-physician staff scheduling. This study calls for the proposed approaches to be thoroughly evaluated.

Originality/value: This article is among a few to investigate physician scheduling, which is essential for delivering timely, high-quality care. Several improvement opportunities are not exclusive to physician scheduling, but are pervasive in healthcare generally.

Keywords: Personnel staffing and scheduling, Quality improvement, Hospitals

\section{Introduction}

Timeliness is a healthcare quality dimension (Institute of Medicine, 2001, p.6) that raises concerns in several countries (Health Consumer Powerhouse, 2009), particularly in Sweden (Thor et al., 2004). Timing is important for realizing good medical outcomes, achieving high patient-satisfaction and enabling other healthcare quality dimensions, such as efficiency (Garg 
et al., 2010). Poor timing mainly affects publicly funded healthcare (Hoel and Sæther, 2003) and can be corrected using different strategies (Dimakou et al., 2009). Some strategies are grounded on the premise that poor timeliness is typically not a resource problem, which can be ameliorated using existing resources (Haraden and Resar, 2004; van der Voort et al., 2010). Mismatches between demand and capacity cause poor timeliness (Silvester et al., 2004; Walley et al., 2006) and mismatches between demand and capacity are largely managed by schedulers, who decide resource availability by granting vacation and leave requests and distributing available resources among different assignments operating in the healthcare unit. Physician scheduling is particularly important as physicians are frequently considered the bottleneck in healthcare processes (Schall et al., 2004), since they are the most expensive healthcare resource and influence how the remaining resources are used. Physician scheduling is thus crucial for high-quality and timely care. However, despite its importance, physician scheduling remains largely unexplored. Physician scheduling is about managing (including granting vacation and leave requests) and distributing physician time among the assignments carried out in hospitals; in wards, surgery, outpatient clinic and emergency departments. Besides scheduling decisions (i.e., tactical), Warner (1976) argues that managing staff requires making decisions strategically and operationally. These decisions deal with determining the staff required for each skill and readjusting the daily schedule to unforeseen events, respectively (Bourdais et al., 2003). We aim to describe current physician scheduling and concomitant opportunities to improve the process in public hospital departments.

\section{Theory}

Staff scheduling has been profusely investigated, especially in the service sector. Frequently studied applications include call centres, transportation and healthcare systems (Ernst et al., 2004ab). Staff scheduling in the service sector is challenging as demand typically varies greatly throughout the day and from day to day (ibid). Staff scheduling problems can be classified into: (i) demand forecasting; (ii) days off; (iii) shifts; (iv) work-line construction (or tour scheduling); (v) task assignment; and (vi) staff assignment (ibid). Blöchliger (2004) provides a general tutorial on how to model staff scheduling problems.

There are several studies on nurse scheduling in contrast to only a few physician studies. Brunner et al., (2009, p.286) argue that "the problem of physician scheduling has received much less attention [than nurse scheduling] and for the most part, is still done manually at great time and expense". Existing physician-scheduling studies address issues such as: (i) scheduling emergency room physicians (Innes et al., 2005; Gendreau et al., 2007; Yang et al., 2009; Ferrand et al., 2011); (ii) scheduling teaching in training programs (Cohn et al., 2006) and (iii) scheduling hospital rounds by speciality for teams (White and White, 2003). Recently, models that allow physician scheduling, using flexible shifts and physician experience have been developed and tested using anesthesia department data (Brunner et al., 2009; Brunner and Edenharter, 2011). Stolletz and Brunner (2012) expanded physician scheduling by using flexible shifts and integrating physician preferences and fairness into the scheduling model.

Contrary to physicians, nurse scheduling has been intensively researched. Many nursescheduling models cannot easily be applied to physician scheduling as the latter is a more complex process (Brunner et al., 2009; Brunner and Edenharter, 2011; Stolletz and Brunner, 2012), owing to high physician specialization, their wide-ranging activities, varying labor contracts (Hedlund, 2011) and the varying demand for physician services (Vaziri et al., 2007). It is more difficult to define the generally accepted constraints for physicians than for nurses. Nurse scheduling is mainly uniform across hospitals, physician scheduling is much more hospital-centric. The increased complexity also makes creating satisfactory physician 
schedules more difficult to achieve. Cheang et al., (2003); Burke et al., (2004) mention three common nurse-scheduling approaches: (i) traditional scheduling (also called personalized schedules or preference schedules); (ii) cyclic scheduling (also called rotation schedules) and (iii) self-scheduling (Warner, 1976; Bourdais et al., 2003). The earliest approaches used cyclic scheduling because it could be performed manually or with little computational effort. Despite their advantage, cyclic schedules do not provide enough flexibility (Bard and Purnomo, 2005). The recent nursing shortage has given nurses greater influence on scheduling to improve their working conditions (Rönnberg and Larsson, 2010). Nurse preferences have lately been given greater consideration, including shift-length, days-on and off patterns and preferred working co-partners (Burke et al., 2004; Bard and Purnomo, 2005). Non-cyclic scheduling offers more flexibility and it accommodates staff preferences, such as self-scheduling (e.g., Karlsson, 2005), which is gaining popularity. Despite these advantages (Bailyn et al., 2007), self-scheduling can be time-consuming and lead to frequent conflicts (Rönnberg and Larsson, 2010). Self-scheduling can also make it difficult to ensure fairness among the scheduled staff (De Grano et al., 2009). Factors other than fairness, when evaluating a schedule, include coverage, quality, stability, flexibility and cost (Warner, 1976).

\section{Method}

As department-level physician-scheduling research is scarce, we designed an exploratory study that followed a qualitative and inductive approach. Moreover, since physician scheduling occurs discontinuously and the process can hardly be observed, qualitative interviews (Kvale and Brinkmann, 2009) were deemed to be optimally suited to collecting data. There was no theoretical model to guide data collection, so the study was unstructured. Scheduling documents were also data sources. We used case studies (Bryman, 2007) to investigate physician scheduling in several organizations, as case studies are a favored design for exploratory studies (Lee, 1998). Physician scheduling was studied in 13 hospital departments spread geographically across Sweden and covering seven different specialties: (i) two dermatology; (ii) three internal medicine; (iii) one obstetric and gynaecology; (iv) two ophthalmology; (v) one orthopaedic; (vi) one paediatric; and (vii) three surgery departments. All were in publicly funded hospitals providing specialty care.

Data were collected through interviews with staff who created physician schedules to gain insight into scheduling, its steps and opportunities for improvement. No interdependencies in physician scheduling existed across the hospital departments we investigated. Interviews lasted approximately two hours. Some informants requested group interviews. While group interviews risk domination by a few influential interviewees, problems can be discussed that the interviewees might omit if interviewed individually (Kvale and Brinkmann, 2009). The authors acceded to group interviews because the method seemed to have no major disadvantages. In all the hospital departments we investigated, the department chair person was asked to identify appropriate interviewees who could comprehensively and accurately describe current physician scheduling and the opportunities for improvement. All interviews were held at the respective clinics and conducted by the first author. Although social desirability bias emerges in many inquiry situations (Bryman and Bell, 2007), this potential bias was arguably irrelevant in this study since scheduling tends to be perceived as a mere support process, lying outside the scheduling teams' core medical competence. The study's non-medical nature may thus have enhanced a free description of the current process and its shortcomings. Besides giving interviews, the scheduling teams provided physician-scheduling documents and the different schedule templates they used.

We used a "summarizing qualitative content analysis" approach (Flick, 2009, p.325) to data analysis; i.e., less relevant passages were deleted and the rest grouped according to 
similarity and summarized. The interpretation required by the authors was low as data were mainly objective. Reduction and synthesis allowed commonalities in physician scheduling across all hospital departments we investigated to be identified. Thus, a six-step physician scheduling process and eight opportunities for improvements emerged. Although data were collected exclusively by one author, the analysis was performed by both authors to improve objectivity (Eisenhardt, 1989).

\section{Findings}

As hospital departments belonged to different specialties and different hospitals, staff and their contractual conditions and assignments differed. Nevertheless, there were many similarities concerning the steps and opportunities for improving physician scheduling.

\section{Physician scheduling team}

Physician scheduling was undertaken by a team: department chair; main scheduler and at least one assistant scheduler. The department chair and the main scheduler were physicians, whereas assistant schedulers were secretaries or nurses. The department chair usually granted vacation and leave requests and in some cases also was the main scheduler; i.e., distributing assignments among physicians and resolving unstaffed assignments. Assistant schedulers dealt with tasks such as checking room and equipment availability, improving schedule layout and entering physician schedules into appointment books.

\section{Physician scheduling process}

A six-step physician scheduling process emerged from the data (Figure 1). Over one-year, steps 1 and 2 were carried out approximately once a year and were the foundations for physician scheduling. Steps 4 to 6 were conducted more frequently, as physician schedules were released periodically with a frequency ranging from one to two months depending on the department. Depending on their nature, vacation and leave requests (step 3) were granted continuously; i.e., when submitted, or in a batch-like manner in connection with creating physician schedules.

\section{Figure 1 here}

The steps identified can be described as follows:

1. Capacity and demand: Physician scheduling requires attention to service demands. There were annual productivity goals for most services according to department funding. Physician scheduling also required attention to capacity; i.e., physicians available to meet service demand. At this stage, physician availability and competence were recorded.

2. Demand, goal and schedule setting: At this stage, some scheduling teams defined demand models with measurable goals over a certain times. Demand for services was either expressed as patient numbers or physician time required. The latter was calculated using historical data. To continuously match demand and capacity, the scheduling teams followed different strategies:

- Minimum staffing level: defining the least physicians needed to keep the department going as some key assignments had to be staffed continuously.

- Minimum assignment level: defining which assignments were compulsory; i.e., assignments that always have priority over vacation and leave requests.

- Desired assignment level: defining both compulsory and non-compulsory assignments. The latter included lower priority assignments, which depended on staffing capacity. 
- Cyclic schedule: staffing compulsory and non-compulsory assignments with specific physicians. For some assignments, the cyclic schedule considered job rotation among physicians. Two cyclic schedules emerged: normal staffing and reduced staffing. The latter usually applied to summer and Christmas periods and excluded almost all elective assignments.

3. Vacation and leave requests: In many cases, requests were granted without knowing which physicians would be available to meet service demands. Depending on their nature, vacation and leave requests were granted continuously; i.e., as soon as they were submitted, or in a batch-like way when physician schedules were created.

4. Schedule creation: Creating the schedule usually had granting vacation and leave requests as its starting point and proceeded with staffing compulsory assignments, such as on-call, emergency care and ward rounds. Thereafter, there was some variation in assignment priority. Surgery tended to be given higher priority, whereas outpatient assignments were lower. This stage required coordinating patients, physician and non-physician staff, rooms and equipment. Creating physician schedules was said to resemble fitting a puzzle together with several dependencies that needed considering. Three layouts were produced: (i) physician (showing assignments scheduled over time for each physician); (ii) assignment (showing staffing over time for each assignment) and (iii) room (showing assignments scheduled over time for each room).

5. Schedule revision: The final schedule was typically preceded by several intermediary versions in which scheduled physicians had requested changes and errors corrected. Integrating different parts put high requirements on efficient communication inside the scheduling team, among scheduling teams and between the scheduling team and the physicians. Once finalized, the schedule was distributed to physicians and posted at a designated spot in the department.

6. Schedule execution: Physicians were sometimes allocated to several assignments simultaneously; e.g., emergency department, ward rounds and outpatients. Distributing time among different tasks was left to physician discretion, which could lead to assignments being left unstaffed for long periods, especially in the emergency department. Furthermore, the chair in some hospital departments allowed physicians to cancel assignments without notifying the main scheduler and regardless of whether patients were already booked for that assignment.

Opportunities for improvement and challenges to current physician scheduling Some scheduling aspects were problematic:

1. Overreliance on memory: Most interviewees stressed the difficulties producing physician schedules and claimed that much information was in the schedulers' minds; e.g., physicians' preferences for and skills in performing different assignments.

2. Uncoordinated resources: Some errors emerging from physician schedules were: (i) double-booking physicians; (ii) scheduling absent physicians; (iii) scheduling assignments for which no room or equipment was available; (iv) scheduling physicians for a longer periods than permitted by labor legislation; (v) the mismatch between physician and nurse schedules; and (vi) unpaired supervision and training assignments.

3. Redundant-data entry: There were occasions when existing data needed to be reentered into another location: (i) vacation and leave requests had to be re-entered into the schedule; (ii) scheduled outpatient clinic assignments had to be transferred to the appointment book; and (iii) scheduled on-call assignments and subsequent leave had 
to be reported in another system. Moreover, converting the schedule into different layouts; i.e., physician, assignment and room, was done manually.

4. Lacking follow-up data: Interviewees received complaints from physicians about the scarce time allotted for administration or for assignments particularly appreciated by physicians; e.g., surgery assignments. Controversy and unfairness often persisted as data about scheduled and completed assignments were not continuously collected. Occasional data on allocated time per physician and assignment; e.g., night on-call assignments per physician during a certain period, were collected manually and suggested that the physicians who used to complain most about their schedules had their requests more frequently granted.

5. Mismatches between demand and capacity: According to the interviewees, mismatches were frequent and to some degree perceived as inevitable considering the multiple factors affecting physician scheduling. These mismatches mainly affected the less prioritized assignments and were allowed to accumulate over time. Mismatch records were not kept but when it was perceived that patient waiting times for a certain assignment were excessive, additional time was allocated to that assignment.

6. Highly varying physician availability: Some interviewees reported that physicians allocated to the lowest prioritized assignments varied greatly over time. Conversely, total nurses available to assist physicians in outpatient assignments remained stable, a mismatch that resulted in uneven workloads for nurses.

7. Uninformed vacation and leave requests: The department chair granted requests with scant information about meeting service demand in upcoming schedules, especially for the non-compulsory assignments, resulting in unstaffed assignments, which if unresolved, led to cancellations and subsequent imbalances between demand and capacity.

8. Conflicting stakeholder-interests: Interviewees said it was crucial to keep physicians satisfied owing to physician shortage. Keeping physicians satisfied seemed to be most important for the scheduling teams located in less attractive geographical areas. Some interviewees maintained that physician interests and preferences occasionally conflicted with other stakeholder interests.

\section{Discussion}

Despite their detrimental effect on timeliness (Silvester et al., 2004; Walley et al., 2006), mismatches between capacity and demand were frequent in physician scheduling. Arguably, these mismatches resulted from fragmentation, missing computerized decision support systems (DSSs) and absent learning opportunities. Persistent staff shortage or inefficient work, are peripheral to physician scheduling and are, therefore, excluded.

\section{Excessive fragmentation}

Scheduling healthcare resources is a process whereby several interrelated activities are repeated to create value for external or internal customers (Bergman and Klefsjö, 2010) and whereby schedulers deploy interdependent resources, such as physicians, nurses, rooms and equipment to create schedules that ensure timeliness, efficiency and staff satisfaction. This is a support process as scheduling provides resources for the main clinical processes (Bergman and Klefsjö, 2010).

To accommodate professional cleavages (Glouberman and Mintzberg, 2001a), the scheduling process has become fragmented and is currently decomposed into interdependent sub-processes; e.g., physician and nurse scheduling. Decomposing the process into subprocesses may increase miscommunication and misaligned purpose, which places great 
importance on integrating sub-process adequately. Interviewees mentioned several mismatches when using various resources resulting from miscommunication. Concerning misaligned purpose, interviewees explained that keeping physicians satisfied is crucial and that this may divert schedulers' focus from matching service demand to accommodating staff preferences.

To alleviate the shortcomings resulting from excessive fragmentation, two approaches were distinguished: (i) either reducing total sub-processes into which scheduling is currently decomposed or (ii) integrating sub-processes. The latter approach can be accomplished through different mechanisms, such as standardizing work and outputs (Glouberman and Mintzberg, 2001b), which can be achieved by using a DSS. The former approach can be accomplished by centralizing scheduling into fewer scheduling teams; e.g., having a single team creating schedules for physicians and nurses. This would enable better resource utilization and increase the scheduling team's freedom when allocating healthcare resources. Centralizing the scheduling could also mitigate conflicts of interests among different stakeholders involved in scheduling and reinforce patients' interests, especially concerning timeliness.

\section{Lacking decision support}

Current physician scheduling is conducted manually using paper and pen or, at best, helped by spreadsheets and text documents. Absent DSSs in physician scheduling may explain scheduling's perceived complexity and time requirements. Several shortcomings can be overcome by using DSSs; e.g., the heavy reliance placed on the schedulers' memory and difficulties matching different resources. By using DSS, physician scheduling could be done automatically, thus saving time for the schedulers that could alternatively be allocated to clinical assignments. Decision support systems could allow practitioners to benefit from previous research as the models developed for scheduling by researchers are calculation intensive and almost always require computers (Burke et al., 2004; Kellogg and Walczak, 2007). Scarce follow-up data on completed assignments could be solved as the DSS would track weekend on-call assignments per physician, thus promoting scheduling fairness. Timeliness could also be enhanced by using DSS as imbalances between demand and capacity over time would be recorded and changes in waiting times could easily be predicted. Overall, DSS-enabled data collection is important for monitoring and improving physician scheduling (Harrington, 1991; Davenport, 1993; Thor et al., 2008). Decision support systems could bolster timeliness by supporting the scheduler who grants vacation and leave requests. Increased transparency and accountability could even mitigate conflicts of interests and enhance staff commitment to meeting service demand. Thus, DSSs can ameliorate several shortcomings identified by interviewees and enable timeliness, efficiency and staff satisfaction (Ernst et al., 2004b).

Despite their numerous potential benefits, DSSs are no panacea; they cannot be expected to fix unclear goals or an entitlement culture (Douglas, 2011). Instead, DSSs should be used as catalysts to re-examine, refresh and renew scheduling practices at the same time as they bring evidence into the picture. Fitting DSSs to current operations is important for ensuring that DSSs are adopted (Classen, 1998; O'Connell et al., 2004; Varonen et al., 2008), therefore scheduling DSSs should be integrated into existing computerized systems, such as appointment books and administrative systems.

\section{Learning opportunities}

Interviewees described current physician scheduling as complex and time-consuming, which is consistent with previous research (Brunner et al., 2009). Moreover, physician scheduling 
was characterized by frequent mismatches between demand and capacity, and staff dissatisfaction with schedules. Interviewees said that they lacked education in scheduling and that the task was done to the best of their abilities and with little exchange of experiences about scheduling with staff in other organizations. Consequently, learning about scheduling resources needs to be stimulated to improve current physician scheduling and enable timeliness, efficiency and staff satisfaction.

Learning about physician scheduling should occur at multiple levels: (i) individual scheduler; (ii) physician-scheduling team; (iii) across scheduling teams working with interdependent resources; e.g., physician and nurse scheduling; and (iv) across scheduling teams that do not share interdependent resources. The latter level; i.e., cross-organizational learning, is particularly important for disseminating best practices (Berwick, 2003) and establishing uniform terminology for healthcare scheduling. Organizational learning should occur across specialties, hospitals and even activity sectors as there is much to learn about how staff in other sectors schedule their workforce (Johnston and Clark, 2008). Nevertheless, higher learning and improvement potential derived from non-healthcare organizations are negated by the increased difficulties understanding and translating lessons gained from these organizations.

Despite its advantages, creating learning opportunities may be compromised by current cost-containing strategies. Nevertheless, reduced competition among publicly financed hospitals should enable cross-organizational learning within healthcare. Quality collaboratives can bolster cross-organizational learning as they can be highly effective in motivating and providing knowledge, skills and support to participants (Øvretveit et al., 2002). The ultimate purpose of creating learning opportunities is to promote continuous improvement and achieve behavioral change. Didactic education, for example, is ineffective in promoting behavioral change (Prior et al., 2008).

\section{Future research}

This exploratory study raises several questions that require further investigation. Problem frequency and the relative importance of improvement opportunities we identified need to be studied along with the proposed approaches' feasibility and effects. Particularly, eventual DSSs should be piloted and evaluated. Likewise, mismatches between capacity and demand should be examined to understand whether capacity varies more than demand and whether poor timeliness is mainly attitudinal.

\section{Limitations and generalizability}

Only persons involved in creating physician schedules were interviewed. Other stakeholders, such as scheduled physicians, nurses and patients, could provide a richer physician-scheduling picture, but with increased resource consumption. Total hospital departments investigated and similarity in physician scheduling across departments reinforce the generalizability, especially to other publicly financed hospital departments. Generalizing findings to private healthcare is inadvisable since physician schedules differ owing to hospital ownership (Mache et al., 2009), so there may be differences in physician scheduling. Generalizing the findings to primary care is similarly inappropriate as fewer staff and assignments make primary care physician scheduling easier. Generalizing the findings to non-physician staff also requires some caution.

\section{Conclusions}

Physician scheduling plays a major role in timely patient care. This has been insufficiently emphasized in previous research, which has barely addressed hospital physician scheduling, which is a complex process that requires coordinating physician and non-physician staff, and 
the rooms and equipment they use. Scheduling is affected by service demand, organizational goals, physician preferences and skills, and working time legislation. Physician scheduling can be described as a six-step process with opportunities for improvement regarding overreliance on memory, poorly coordinated resources and redundant-data entry. The approaches proposed for improving physician scheduling range from reinforcing centralization and improving integration to creating additional learning opportunities. Several shortcomings that we identify are not exclusive to physician scheduling but are pervasive in healthcare processes generally.

\section{References}

Bailyn, L., Collins, R. and Song, Y. (2007), 'Self-scheduling for hospital nurses: an attempt and its difficulties', Journal of Nursing Management, Vol. 15 No. 1, pp. 72-77.

Bard, J.F. and Purnomo, H.W. (2005), 'Preference scheduling for nurses using column generation', European Journal of Operational Research, Vol. 164 No. 2, pp. 510-534.

Bergman, B. and Klefsjö, B. (2010), Quality from Customer Needs to Customer Satisfaction, $3^{\text {rd }}$ ed., Studentlitteratur AB, Lund.

Berwick, D.M. (2003), 'Disseminating Innovations in Health Care', Journal of the American Medical Association, Vol. 289 No. 15, pp. 1969-1975.

Blöchliger, I. (2004), 'Modeling staff scheduling problems. A tutorial', European Journal of Operational Research, Vol. 158 No. 3, pp. 533-542.

Bourdais, S., Galinier, P. and Pesant, G. (2003), 'HIBISCUS: A constraint programming application to staff scheduling in health care', in Rossi, F. (Ed.), Principles and Practice of Constraint Programming - Cp 2003, Proceedings, Vol. 2833, pp. 153-167.

Brunner, J.O., Bard, J.F. and Kolisch, R. (2009), 'Flexible shift scheduling of physicians', Health Care Management Science, Vol. 12 No. 3, pp. 285-305.

Brunner, J.O. and Edenharter, G.M. (2011), 'Long term staff scheduling of physicians with different experience levels in hospitals using column generation', Health Care Management Science, Vol. 14 No. 2, pp. 189-202.

Bryman, A. (2007), 'Barriers to Integrating Quantitative and Qualitative Research', Journal of Mixed Methods Research, Vol. 1 No. 1, pp. 8-22.

Bryman, A. and Bell, E. (2007), Business Research Methods, $2^{\text {nd }}$ ed., Oxford University Press, New York.

Burke, E.K., de Causmaecker, P., Berghe, G.V. and van Landeghem, H. (2004), 'The State of the Art of Nurse Rostering', Journal of Scheduling, Vol. 7 No. 6, pp. 441-499.

Cheang, B., Li, H., Lim, A. and Rodrigues, B. (2003), 'Nurse rostering problems - a bibliographic survey', European Journal of Operational Research, Vol. 151 No. 3, pp. 447-460.

Classen, D.C. (1998), 'Clinical Decision Support Systems to Improve Clinical Practice and Quality of Care', Journal of the American Medical Association, Vol. 280 No. 15, pp. 1360-1361.

Cohn, A., Root, S., Esses, J., Kymissis, C. and Westmoreland, N. (2006), Using Mathematical Programming to Schedule Medical Residents, Boston University School of Medicine, Boston.

Davenport, T.H. (1993), Process Innovation: Reengineering Work Through Information Technology, Harvard Business School Press, Boston.

de Grano, M.L., Medeiros, D. and Eitel, D. (2009), 'Accommodating individual preferences in nurse scheduling via auctions and optimization', Health Care Management Science, Vol. 12 No. 3, pp. 228-242. 
Dimakou, S., Parkin, D., Devlin, N. and Appleby, J. (2009), 'Identifying the impact of government targets on waiting times in the NHS', Health Care Management Science, Vol. 12 No. 1, pp. 1-10.

Douglas, K. (2011), 'What Every Nurse Executive Should Know About Staffing And Scheduling Technology Initiatives', Nursing Economic\$, Vol. 29 No. 5, pp. 273-275.

Eisenhardt, K.M. (1989), 'Building Theories from Case Study Research', Academy of Management Review, Vol. 14 No. 4, pp. 532-550.

Ernst, A.T., Jiang, H., Krishnamoorthy, M., Owens, B. and Sier, D. (2004), 'An Annotated Bibliography of Personnel Scheduling and Rostering', Annals of Operations Research, Vol. 127 No. 1, pp. 21-144.

Ernst, A.T., Jiang, H., Krishnamoorthy, M. and Sier, D. (2004), 'Staff scheduling and rostering: A review of applications, methods and models', European Journal of Operational Research, Vol. 153 No. 1, pp. 3-27.

Ferrand, Y., Magazine, M., Rao, U.S. and Glass, T.F. (2011), 'Building Cyclic Schedules for Emergency Department Physicians', Interfaces, Vol. 41 No. 6, pp. 521-533.

Flick, U. (2009), An Introduction to Qualitative Research, $4^{\text {th }}$ ed., Sage Publications Ltd., London.

Garg, L., McClean, S., Meenan, B. and Millard, P. (2010), 'A Non-Homogeneous Discrete Time Markov Model for Admission Scheduling and Resource Planning in a Cost or Capacity Constrained Healthcare System', Health Care Management Science, Vol. 13 No. 2, pp. 155-169.

Gendreau, M., Ferland, J., Gendron, B., Hail, N., Jaumard, B., Lapierre, S., Pesant, G. and Soriano, P. (2007), 'Physician scheduling in emergency rooms', in E. K. Burke and H. Rudova (Eds.), Practice and Theory of Automated Timetabling VI, Vol. 3867, pp. 5366.

Glouberman, S. and Mintzberg, H. (2001a), 'Managing the Care of Health and the Cure of Disease-Part I: Differentiation', Health Care Management Review, Vol. 26 No. 1, pp. 56-69.

Glouberman, S. and Mintzberg, H. (2001b), 'Managing the Care of Health and the Cure of Disease-Part II: Integration', Health Care Management Review, Vol. 26 No. 1, pp. 7084.

Haraden, C. and Resar, R. (2004), 'Patient Flow in Hospitals: Understanding and Controlling It Better', Frontiers of Health Services Management, Vol. 20 No. 4, pp. 3-14.

Harrington, H.J. (1991), Business Process Improvement: The Breakthrough Strategy for Total Quality, Productivity, and Competitiveness, McGraw-Hill, New York.

Health Consumer Powerhouse. (2009), Euro Health Consumer Index 2009, Health Consumer Powerhouse AB, Brussels.

Hedlund, A. (2011), 'Läkaryrket - inte ett kall men en genväg till ökad fritid', Läkartidningen, Vol. 41, pp. 12-18 (in Swedish).

Hoel, M. and Sæther, E.M. (2003), 'Public health care with waiting time: the role of supplementary private health care', Journal of Health Economics, Vol. 22 No. 4, pp. 599-616.

Innes, G.D., Stenstrom, R., Grafstein, E. and Christenson, J.M. (2005), 'Prospective time study derivation of emergency physician workload predictors', Canadian Journal of Emergency Medicine, Vol. 7 No. 5, pp. 299-308.

Institute of Medicine. (2001), Crossing the Quality Chasm: A New Health System for the 21st Century, The National Academies Press, Washington D.C.

Johnston, R. and Clark, G. (2008), Service Operations Management: Improving Service Delivery, $3^{\text {rd }}$ ed., Prentice Hall, Harlow. 
Karlsson, P. (2005), Rapport om kartläggning av arbetstidslösningar inom landstinget: Stockholm läns landsting, Stockholm, (in Swedish).

Kellogg, D.L. and Walczak, S. (2007), 'Nurse scheduling: from academia to implementation or not?', Interfaces, Vol. 37 No. 4, pp. 355-369.

Kvale, S. and Brinkmann, S. (2009), Den Kvalitativa Forskningsintervjun, $2^{\text {th }}$ ed., Studentlitteratur AB, Lund (in Swedish).

Lee, T.W. (1998), Using Qualitative Methods in Organizational Research, Sage Publications, London.

Mache, S., Scutaru, C., Vitzthum, K., Quarcoo, D., Schoffel, N., Welte, T., Klapp, B. and Groneberg, D. (2009), 'Does type of hospital ownership influence physicians' daily work schedules? An observational real-time study in German hospital departments', Human Resources for Health, Vol. 7 No. 41, pp. 1-8.

O'Connell, R.T., Cho, C., Shah, N., Brown, K. and Shiffman, R.N. (2004), 'Take Note(s): Differential EHR Satisfaction with Two Implementations under One Roof', Journal of the American Medical Informatics Association, Vol. 11 No. 1, pp. 43-49.

Øvretveit, J., Bate, P., Cleary, P., Cretin, S., Gustafson, D., McInnes, K., McLeod, H., Molfenter, T., Plsek, P., Robert, G., Shortell, S. and Wilson, T. (2002), 'Quality collaboratives: lessons from research', Quality \& Safety in Health Care, Vol. 11 No. 4, pp. 345-351.

Prior, M., Guerin, M. and Grimmer-Somers, K. (2008), 'The Effectiveness of Clinical Guideline Implementation Strategies - A Synthesis of Systematic Review Findings', Journal of Evaluation in Clinical Practice, Vol. 14 No. 5, pp. 888-897.

Rönnberg, E. and Larsson, T. (2010), 'Automating the self-scheduling process of nurses in Swedish healthcare: a pilot study', Health Care Management Science, Vol. 13 No. 1, pp. 35-53.

Schall, M.W., Duffy, T., Krishnamurthy, A., Levesque, O., Mehta, P., Murray, M., Parlier, R., Petzel, R. and Sanderson, J. (2004), 'Improving patient access to the Veterans Health Administration's primary care and specialty clinics', Joint Commission Journal on Quality and Safety, Vol. 30 No. 8, pp. 415-423.

Silvester, K., Lendon, R., Bevan, H., Steyn, R. and Walley, P. (2004), 'Reducing Waiting Times in the NHS: Is Lack of Capacity the Problem?', Clinician in Management, Vol. 12 , pp. $105-111$.

Stolletz, R. and Brunner, J.O. (2012), 'Fair optimization of fortnightly physician schedules with flexible shifts', European Journal of Operational Research, Vol. 219 No. 3, pp. 622-629.

Thor, J., Herrlin, B., Wittlöv, K., Skår, J., Brommels, M. and Svensson, O. (2004), 'Getting Going Together: Can Clinical Teams and Managers Collaborate to Identify Problems and Initiate Improvement?', Quality Management in Healthcare, Vol. 13 No. 2, pp. 130-142.

Thor, J., Herrlin, B., Wittlöv, K., Øvretveit, J. and Brommels, M. (2008), 'Evolution and outcomes of a quality improvement program', International Journal of Health Care Quality Assurance, Vol. 23 No. 3, pp. 312-327.

Walley, P., Silvester, K. and Steyn, R. (2006), 'Managing Variation in Demand: Lessons from the UK National Health Service', Journal of Healthcare Management, Vol. 51 No. 5, pp. 309-320.

van der Voort, M.R., van Merode, F. and Berden, B. (2010), 'Making Sense of Delays in Outpatient Specialty Care: A System Perspective', Health Policy, Vol. 97 No. 1, pp. 4452. 
Warner, D.M. (1976), 'Scheduling Nursing Personnel According to Nursing Preference: A Mathematical Programming Approach', Operations Research, Vol. 24 No. 5, pp. 842856.

Varonen, H., Kortteisto, T. and Kaila, M. (2008), 'What May Help or Hinder the Implementation of Computerized Decision Support Systems (CDSSs): A Focus Group Study with Physicians', Family Practice, Vol. 25 No. 3, pp. 162-167.

Vaziri, K., Roland, J.C., Robinson, L. and Fakhry, S.M (2007), 'Optimizing Physician Staffing and Resource Allocation: Sine-Wave Variation in Hourly Trauma Admission Volume', The Journal of Trauma and Acute Care Surgery, Vol. 62 No. 3, pp. 610-614.

White, C. and White, G. (2003), 'Scheduling Doctors for Clinical Training Unit Rounds Using Tabu Optimization: Practice and Theory of Automated Timetabling IV', in Burke, E. and de Causmaecker, P. (Eds.), Vol. 2740, pp. 120-128, Springer, Berlin/Heidelberg.

Yang, C.C., Lin, W.T., Chen, H. M. and Shi, Y.H. (2009), 'Improving scheduling of emergency physicians using data mining analysis', Expert Systems with Applications, Vol. 36 No. 2 Part 2, pp. 3378-3387.

Figure 1: The physician scheduling process in public hospital departments

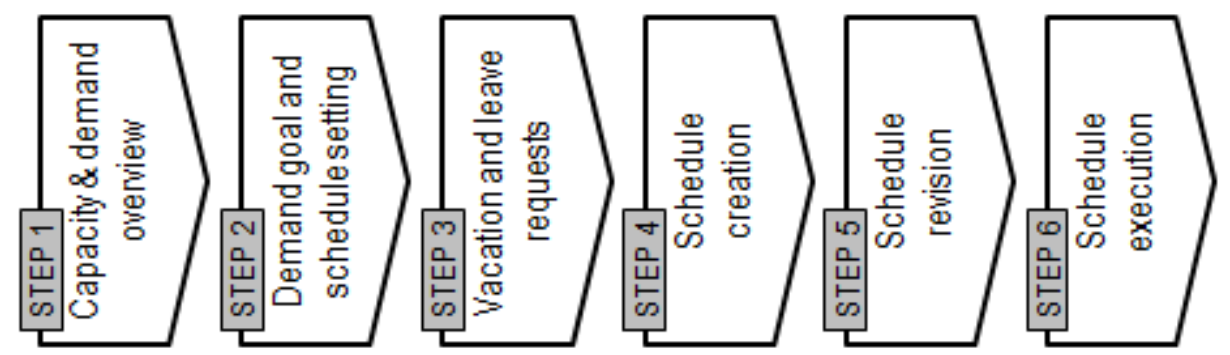

